NASA Technical Memorandum 85911

NASA-TM-85911

19850001727

\title{
Rotor Systems Research Aircraft Airplane Configuration Flight-Test Results
}

W. D. Painter and D. E. Erickson

\section{4}

LANGLEY FESEARR:- CENTER

LIBRARY, NASA

HAMPTON, VIRGINIA 
NASA Technical Memorandum 85911

\section{Rotor Systems Research Aircraft Airplane Configuration Flight-Test Results}

W. D. Painter

NASA Ames Research Center, Dryden Flight Research Facility, Edwards, California

R. E. Erickson

NASA Ames Research Center, Moffett Field, California

\section{N/SA}

National Aeronautics and

Space Administration

Ames Research Center

Dryden Flight Research Facility

Edwards, California 93523 


\author{
W. D. Painter* \\ NASA Ames Research Center \\ NASA Ames Dryden Flight Research Facility \\ Edwards, California \\ and \\ R. E. Erickson ${ }^{\dagger}$ \\ NASA Ames Research Center \\ Moffett Field, California
}

\begin{abstract}
The Rotor Systems Research Aircraft (RSRA) has been undergoing ground and flight tests by Ames Research Center since late 1979, primarily as a compound aircraft. The purpose was to train pilots and to check out and develop the design flight envelope established by the Sikorsky Aircraft Company. This paper reviews the preparation and flight test of the RSRA in the airplane, or fixedwing, configuration and discusses the results of that test.
\end{abstract}

\section{Nomenc1ature}

$\mathrm{C}_{\mathrm{n}_{\beta}}=$ yawing moment due to sideslip

$r \cdot g \cdot=$ center of gravity, longitudinal

$\mathrm{CPU}=$ control phasing unit (changes sensitivity and range of rotary and fixed-wing control surfaces)

FSAA $=$ F1ight Simulator for Advanced Aircraft

G.W. = gross weight

$\mathrm{H}_{\mathrm{d}}=$ density a1titude

$I_{w} \quad=$ wing incidence angle

$\mathrm{KCAS}=$ knots calibrated airspeed

KIAS $=$ knots indicated airspeed

KTAS $=$ knots true airspeed

WL = waterline station

\section{Introduction}

The Rotor Systems Research Aircraft (RSRA) ${ }^{1,2}$ was designed as a pure research aircraft and dedicated rotor test vehicle whose function is to fill the void between design analysis, wind tunnel testing, and flight results. The RSRA program

*Project Engineer. Member AIAA.

tResearch Engineer.

This paper is declared a work of the U.S. Government and therefore is in the public domain. has existed since 1970 as shown in Table 1 . The concept originated in the late 1960s when an effort was made to advance the state-of-the-art in rotor systems technology. There was a concern of the inability to predict with any accuracy the characteristics of a new rotor system based on results obtained from flight data. Sikorsky Aircraft was contracted by NASA/Army to deliver two aircraft to provide this capability. One of those alrcraft is being tested by Ames Research Center and the second aircraft, after completing test programs in the pure helicopter configuration is currently being modified for the development and in-flight demonstration of the "X-wing" design. This paper is limited to describing the aircraft and the government flight testing of the airplane configuration at the NASA Ames Dryden F1ight Research Facllity (Ames Research Center).

The ability to measure precisely the exact rotor state as a function of time and flight condition was the critical element that was missing and the one that prevented significant advances in complex rotor systems. The costly method of trial and error exposed a great risk to both the flightcrews and program budgets. A development or modification of an existing airframe was required to match each new rotor system under study; thus, a total aircraft development program was usually necessary. This concept did not allow innovative investigations to depart very far from proven, successful designs. The "flying wind-tunnel" concept of the RSRA is a dedicated rotor test vehicle whose function it is to fill this development need.

In order to be useful, research vehicles must have certain basic capabilities. These capabilities must include the expected flight envelopes of future rotor systems and a versatile flight control system to exploit this envelope. A data acquisition system must provide an accurate measurement and recording of all the desired flight parameters that are needed to perform a comprehensive analysis.

To provide this unique performance capability, there are three configurations of the RSRA: helicopter, compound helicopter, and flxed-wing airplane. ${ }^{1,2}$ The fixed-wing configuration is the same as the compound helicopter but with the rotor removed. The primary purpose of the fixed wing is to provide a fly-back capability should it become necessary to sever an unstable rotor system in flight; this configuration was tested at the Ames Dryden Flight Research Facility. 


\section{Description of the Test Aircraft}

The test alrcraft has a basic helicopter fuselage with the wings and the lower horizontal a11flying stabilator installed. Two auxiliary power plants are mounted on elther side of the fuselage. These GE TF-34, h1gh bypass turbojet englnes are used to offset drag effects when rotor systems are being tested with the alrcraft in the compound configuration and to provide thrust for the airplane configuration. Each eng ine can input $8250 \mathrm{lb}$ of thrust. In the airplane configuration, the RSRA weighs about 28,000 Ib maximum. The conventional helfcopter tall rotor was retained for the airplane configuration flight tests. Two GE 58 engines provide power to the tail rotor and aircraft systems. The 45-ft wing, whose angle of Incidence can be varied between $15^{\circ}$ leading edge up and $9^{\circ}$ leading edge down, was restricted to $15^{\circ}$ leading edge up and $0^{\circ}$ leading edge down. The wing contains conventfonal allerons and flaps, both of which can be operated by an on-board digital computer when 1 t 1s Installed. The computer was not installed for the flxed-wing tests.

The tafl section contains a conventional helicopter tall rotor, a lower horizontal all-flying stabllator, an upper fixed horizontal tall plan, a conventional rudder, and an aft-mounted split-panel drag brake, all can be operated from the cockpit controls or by the electronic flight control system.

\section{Test Objectives}

There were five test objectives: aircraft

1) Demonstrate the RSRA as a fixed-wing

2) Obtain fixed-wing control power and stability data in support of the NASA/DARPA $X-w i n g$ program

3) Develop the flight envelope to 250 knots

4) Obtain baseline main-rotor-off acoustics data

5) Obtain rotor-hub drag data

It was planned to attain the above objectives with and without the main hub rotor installed. The design envelope, with tail rotor instailed, is shown in Fig. 2.

\section{Test Preparation}

When the requirement to demonstrate the RSRA fixed-wing configuration was confirmed, it was first necessary to define the tasks that would prepare the alrcraft and personnel for a safe flight program. This preparation started with an "Action Item List" on which action items were assigned to specific individuals for performance by a specifled date. This action list was modified as necessary at regularly scheduled program meetings. Eventually, the list comprised of more than 60 action items. The most important items were as follows:

1) Reanalysis of aerodynamic predictions

2) Aeroelastic analysis
3) Tail-rotor pitch adjustment

4) Piloted moving base simulation

5) In-flight fixed-wing simulation

6) TF-34 engine thrust control redesign

7) Emergency escape system redesign

8) Landing gear up-rating

9) Landing gear door analysis and modification

10) Low-speed, stall, and spin analysis

11) Test site

12) Administrative planning

Each of these 12 items is discussed in the following paragraphs.

\section{Aerodynamic Predictions}

It was presumed that original analytical predictions by Sikorsky, made in the mid-1970s, were dated and that they probably did not incorporate the results of the last wind-tunnel tests. The new predictions made for this program supported the previous ones, however, and further enhanced our confidence in anticipated stall speeds and aircraft control and stability characteristics. These predictions were performed using the Sikorsky General Helicopter Simulation Program for the RSRA modified to remove the rotors. ${ }^{3}$

Aeroelastic Analysis

The original fixed-wing aeroelastic analysis was reviewed and found adequate. The tail rotor was reanalyzed because of structural and aeroelastic considerations. This opened the analyzed envelope for the tail rotor to 250 KTAS from 200 knots, sea level standard. Three conditions were made requisite: that the tail-rotor pitch remain at $0^{\circ}$ at speeds above 200 knots, that the tip Mach number not exceed unity, and that stdeslip be less than $7^{\circ}$.

\section{Tail Rotor P1tch Adjustment}

To comply with the condition of the tall-rotor structural and aeroelastic analysis and to achieve full authority tall-rotor thrust in each direction, the ta11-rotor pitch was adjusted to provide equal control in each direction and the yaw-control phasIng unit (CPU) was modifled to provide zero pitch. when the yaw CPU lever was placed in the zero rotary control gradient position. Figure 3 shows the function of the CPU yaw control with respect to tailrotor pitch.

\section{Plloted Moving Base Simulation}

A simulation of the RSRA was performed on the six-degree-of-freedom Flight Simulator for Advanced Aircraft (FSAA) at Ames Research Center. A static validation of the simulation was accomplished by comparing data for the compound configuration of the RSRA with FSAA output for the same configuration. The rotor module was then removed from the FSAA program, and the pilots were trained on the simulator for nearly a month. This simulation was quite useful in establishing technique and wing incidence and 
f.lap configurations for takeoff and landings, as well as the other flight regimes. Previous recommendations had specified a $10^{\circ}$.wing incidence $\left(I_{W}\right)$ as optimum, but the piloted simulation showed that an $\mathrm{I}_{\mathrm{W}}$ of $5^{\circ}$ was preferred. Later flight experience substantiated the fidelity of this simulation from a quantitative and a qualitative standpoint. This simulation is documented in Ref. 4.

\section{In-Flight Fixed-Wing Simulation}

Several flights were made with the compound RSRA to investigate flying characteristics of the RSRA at minimal rotor lift. This was accomplished by lowering the collective to full low position. In some high-speed cases, rotor lift was reduced to $2000 \mathrm{lb}$, but at lower speeds it was in the 4000to 8000-1b range. The purpose of this test was to load the wing with the full weight of the aircraft and investigate stal1 speeds and characteristics.

Stall speed was determined (approximately) in the 100- to 110-knot range with full flaps. Stall approach roughness, if any, tended to be masked by vibration of the main rotor. Stall did occur without sudden yaw departure as in the moving-base simulation. The primary characteristic of the sta11 was the sudden and rapid increase of main rotor speed as the main rotor tried to pick up the load. During level f1ight to 150 knots the fuselage provided about $2000 \mathrm{lb}$ of lift. This lift decreased as wing incidence was increased to $10^{\circ}$. Figure 4 shows the effect of flap position on wing 1 ift and drag.

\section{TF-34 Engine Thrust Control Redesign}

The origina1 RSRA auxiliary engine thrust control system (throttle control) had poor fidelity relative to pilot inputs and was unacceptable for fixed-wing f1ight. This was redesigned using F-15 throttle control components including a boost device using engine bleed air pressure. The redesigned system characteristics were very satisfactory.

\section{Emergency Escape System Redesign}

The RSRA was equipped originally with an emergency escape system that featured a blade-severance subsystem and a crew-extraction subsystem. A Stanley Yankee Extraction seat was used. As installed, the operation of this extraction seat was validated to 200 knots only. To obtain improved speed capability for the fixed-wing program, a Martin-Baker MK US $10 \mathrm{LT}$ ejection seat was used. This modification provides an emergency escape envelope from zero altitude-zero speed through the entire design speed range of the RSRA (360 knots).

\section{Landing Gear Up-Rating}

The landing gear of the RSRA, as delivered, was rated to 120 knots on $1 y$. Analysis was performed to extend this rating to 192 knots at a sink rate of $8 \mathrm{ft} / \mathrm{sec}$ for a $28,500 \mathrm{lb}$ vehicle. This extension was required to accommodate the fixedwing configuration for which normal touchdown speeds of 130 knots were planned. Consideration of flaps-up emergency landings and high-density a1titudes raised the possible touchdown speeds to the 160-knot range.
Landing Gear Door Analysis and Modification

On the last flight of the RSRA in the compound configuration, the left main-landing-gear door was blown from the aircraft. Analysis, redesign, and fabrication of a strengthened door were accomp 1 ished. The new door, although analytically validated to 200 knots, was 1 imited to 170 knots maximum in the extended position to reduce the possibility of another failure.

\section{Low-Speed Stal1 and Spin Analysis}

Sta11 speeds were recalculated using the latest version of the RSRA GENHEL model, ${ }^{3}$ to determine sta11 speeds. A stall speed of 110 knots with $I_{W}=5^{\circ}$ and full flaps at 28,500 lb gross weight was confirmed. This result also was supported by the compound low speed, low collective tests of the compound configuration.

Spin-departure tendencies were analyzed by calculating $\mathrm{C}_{\mathrm{n}_{\beta}}$ dynamic from simulation and previous wind-tunnel data. This calculation obtained $\mathrm{C}_{\mathrm{n}_{\beta}}$ dynamic for a range 0.001 to 0.0037 which, per Ref. 5, should provide acceptable stall behavior with no yaw-departure tendency if stall is not prolonged. This result was also supported by the FSAA moving base simulator. Figure 5 presents the descriptive phraseology for specific $C_{n_{\beta}}$, dynamic values.

The stall and spin characteristics were predicted to be acceptable. However, since no specific aerodynamic model testing was performed, it was decided to avoid stall in the test program and limit wing angle of attack to a maximum of $15^{\circ}$.

\section{Test Site}

The RSRA is normally based at Ames Research Center (Moffett Field, Calif.). Since the fixedwing testing would require high-speed taxi tests before first flight and since braking distances were estimated to be long, the RSRA was moved to the Ames Dryden Flight Research Facility (ADFRF), Edwards AFB, Ca1if. where a 15,000-ft runway and a $12,000-\mathrm{ft}$ overrun was available. This was accomplished by a compound configuration ferry flight in two legs (a refueling stop at Vandenberg AFB). The ferry flight took place in December 1983. Upon arrival at $A D F R F$; the main rotor and hub were removed.

\section{Test Administrative Planning}

Preparations for the test required the deve1opment of an RSRA fixed wing operations plan which was written and established the cooperative procedure for Ames Moffett to operate with Ames Dryden: A detalled flight test $\mathrm{p}$ lan was also developed. In addition, a data processing requirements document was written which detailed the telemetry and data processing responsibilities at both Ames Moffett and Ames Dryden. This document also specified the RSRA data-measurement system requirements and 1ayout. 
Test Resu1ts

\section{Taxi Tests}

Familiarization with the ground-handling characteristics and insight into the takeoff flight characteristics of the RSRA were accomplished by three taxi "flights." These taxi flights were conducted without the main-rotor hub which lowered the gross weight to $26,000 \mathrm{lb}$ and lowered the vertical c.g. to wh 219. This represents a vertical c.g. decrease of $6 \mathrm{in}$. from the full compound conf $1 \mathrm{~g}-$ uration. Full instrumentation, telemetry, and radar tracking were used in all taxi tests. The radar tracking used a $\mathrm{C}-\mathrm{b}$ and transponder to give aircraft position to within inches relative. accuracy.

The taxi tests confirmed the selection of $I_{W}=5^{\circ}$ and half flaps for takeoff. Higher wing incidence caused uncomfortable nose-down attitude while holding the aircraft on the ground at speeds well above the stall speed of 110 knots. Since the "at rest" ground attitude for the RSRA is only $2^{\circ}$ nose-up, the probability existed that the tail wheel might be on the ground for takeoff at low wing incldence. On the second taxi flight $\left(\mathrm{I}_{\mathrm{w}}=5^{\circ}\right)$, the aircraft lifted from the ground at 135 knots without touching the tailwheel.

Directional control of the aircraft was adequate at all times. This aircraft has a tail rotor and for that reason yaw-control power is such that no minimum yaw-control speed exists. Heading was maintafned using $\pm 15 \%$ of the control available. Acceleration to 135 knots required slightly less than $3000 \mathrm{ft}$. This gave the pilot time to observe the near-takeoff characteristics of the aircraft and then to decelerate to a stop with minimal use for the brakes. Concern about overheating the brakes was disspelled when the pilot found he could aerodynamically decelerate to less than $90 \mathrm{knots}$, then use the brakes sparingly and could easily be stopped before using all of the $15,000-\mathrm{ft}$ paved. portion of the runway. Brake temperatures rose to only a 1ittle more than half of the permissible even on the repeated runs. Brake stack temperatures were recorded by telemetry and also were displayed to the pilots. Rim temperatures were monitored by surface probes at the end of each run; fans were used to cool the brakes after each run. Stack and rim temperatures were required to show a decline and to be low enough to absorb the temperature rise of a full stop from 120 knots. For brief periods during the second and third taxi tests the aircraft flew and was then immediately landed. In one instance, the radar recorded a 50-ft altitude. All taxi tests were conducted with flight as an option to escape from a hazardous situation. Figure 6 shows the Dryden Aerodynamic Test Range radar data for a taxi run with a lift-off of a few feet. Note that the runway has a slight descent." Figure 7 is a time history of control motions during the taxi run. A confirmation of the airspeed calibration was obtained from radar gound speed in low wind conditions and also from static pressure changes at the boom. The previous calibration was conf 1 rmed:

$\mathrm{KIAS}+10=\mathrm{KCAS}$

\section{First Flight}

The first flight was made on May 8,1984 at 0630. Figures 8 and 9 show takeoff data. The aircraft quickly attained $10,000 \mathrm{ft}$ density test altitude. During climb-out a vibration was noted from the tail area both by the pilot and telemetry. A brief investigation showed that even the smallest amount of flaps eliminated the vibration. Subsequent flights were conducted with $5^{\circ}$ flap settings. Since the flaps were effective, it is believed that turbulence from the inboard wing root streams aft to the lower horizontal stabilator. This turbulence excites the $10 \mathrm{~Hz}$ antisymmetric mode of the stabilator. To avoid any aeroelastic envelope expansion, flight speeds attained were limited to that previously explored by the compound configuration. The remainder of the flight was directed to low-speed landing simulation at altitudes to establish the landing technique and flap and wing configuration. The procedure, considered before flight, was accepted, that is, to use $I_{W}=5^{\circ}$, ful1 flaps, an approach speed of $140 \mathrm{KCAS}$, and slowing to $125 \mathrm{kCAS}$ for landing. Main-wheels-first landings were anticipated. Several low-pass practice approaches were made before the final landing, which was slightly tail-wheel first at near $125 \mathrm{KCAS}$, but otherwise uneventful. The flight lasted $1 \mathrm{hr}$. Figure 10 shows approach and landing data. Pilots' qualitative impression of the RSRA handling was that it was comparable to that of a C-130 Hercules.

\section{Envelope Expansion}

The speed envelope was expanded to 250 KTAS ( $215 \mathrm{KCAS}$ at $10,000 \mathrm{ft} \mathrm{H}_{\mathrm{d}}$ ) in two flights. This was to allow review of data at an intermediate speed before final expansion. Fixed surface damping was a minimum of $3 \%$ for the wing edgewise mode; tail-rotor damping was a minimum of $0.5 \%$ in the edgewise mode $(0.5 \%$ edgewise damping is typical for the S-61 tail rotor). None of the damping ratio trends was decreasing at 250 KTAS. Tail-rotor speed was decreased to $94 \%(648 \mathrm{ft} / \mathrm{sec}$ rotating tip speed) and was in flat pitch above 200 KTAS. This gave a tip Mach number well below 1.0 . As a convenience, the tail rotor was so configured at all flight speeds once at test altitude.

The rotor hub was removed for envelope expansion. Figure 11 shows flight trim data. To obtain comparative vertica1 c.g. and hub drag data, the hub and weights used to simulate the complete rotor were reinstalled. Except to monitor effects of turbulence on the tail rotor no aeroelastic envelope expansion was necessary for the hub-weight configuration.

\section{Experimenta1 Data Acquisition}

Control power and dynamic stability data were acquired by step and reversal inputs at 180 and 230 KTAS. Representative plots of each type are shown in Figs. 12-14.

Stability data for analysis by systems identification methods were obtained by testing sine-shape control inputs, continuously increasing frequency in each axis. Figure 15 is a time history of a pitch sine input. 
Trim data were acquired throughout the test speed range ( 145 to $215 \mathrm{KCAS}$ ) for purposes of determining control trim trends (Fig. 11) and performance and rotor-hub drag measurements. Hub drag measurement capability is described in Ref. 6 . System acoustics signature data with the main rotor removed were to be acquired for the 160 to 215 KCAS speed range during flybys at $492 \mathrm{ft}$ above ground level (AGL) and in $3^{\circ}$ glide slope at 394 ft AGL.

Separate reports will be forthcoming to document 1) control power and stability at two vertical c.g.'s and performance with and without rotor hub; 2) rotor hub drag comparison with hub removed and hub installed; 3) systems identification analysis of aircraft stability; and 4) the acoustics of RSRA with tail rotor only.

\section{Conclusions}

The following are the principal results of these flight tests:

1) The emergency, fixed-wing flying characteristics of the RSRA are satisfactory.

2) The flaps should be extended to $5^{\circ}$ to prevent unnecessary lower stabilator vibrations.

3) The landing gear can be extended and retracted up to $170 \mathrm{KCAS}$.

4) The RSRA operating envelope is expanded to $250 \mathrm{KTAS}$ (215 KCAS).

\section{References}

${ }^{1}$ Ha11, G. W. and Merril1, R. K., "Flight Testing the Rotor Systems Research Aircraft," Society of Experimental Test Pilots 1982 Report to the Aerospace Profession-26th Symposium Proceedings, Sept. 1982.

${ }^{2}$ Ha11, G. W. and Merrill, R. K., "F1ight Testing the Rotor Systems Research Aircraft,". NASA TM-85852 and USAAVRADCOM TM-83-A-1, Oct. 1.983.

${ }^{3}$ Houck, J. A., Moore, F. L., Howlett, J. J., Rellock, K. S., and Browne, M. M., "Rotor Systems Research Aircraft Simulation Mathematical Mode1," NASA TM-78629, Nov. 1977.

${ }^{4}$ Kufeld, R. M., "Rotor Systems Research Aircraft: Fixed-Wing Simulation Results," NASA TM-85863, Dec. 1983 .

${ }^{5}$ Skow, A. M. and Erickson, G. E., "Modern Fighter Aircraft Design for High Angle-of-Attack Maneuvering," AGARD-LS-121, Dec. 1982.

${ }^{6}$ Burks, J. S., "Rotor Systems Research Aircraft (RSRA)-Rotor Force and Moment Measurement System," AIAA Paper 81-2516, Nov. 1981.

Table 1. RSRA development history

\begin{tabular}{|c|c|c|}
\hline & Dec. 1970 & NASA/Army Working Group established \\
\hline 1 & Nov. 1971 & Joint NASA/Army development agreement \\
\hline 1 & Mar. 1973 & Request for proposal (Bel1/sikorsky) \\
\hline 6. & Nov. 1973 & Sikorsky awarded contract \\
\hline 12 & Oct. 1976 & First flight, helicopter \\
\hline 10 & Apr. 1978 & First flight, compound \\
\hline 12 & Feb. 1979 & Helicopter arrives at Ames Research Center \\
\hline 29 & Sept. 1979 & Compound arrives at Ames Research Center \\
\hline 23 & Feb. 1980 & First helicopter flight at Ames Research Center \\
\hline 25 & Nov. 1981 & First compound flight at Ames Research Center \\
\hline 8 & May 1984 & First flight, airplane \\
\hline
\end{tabular}




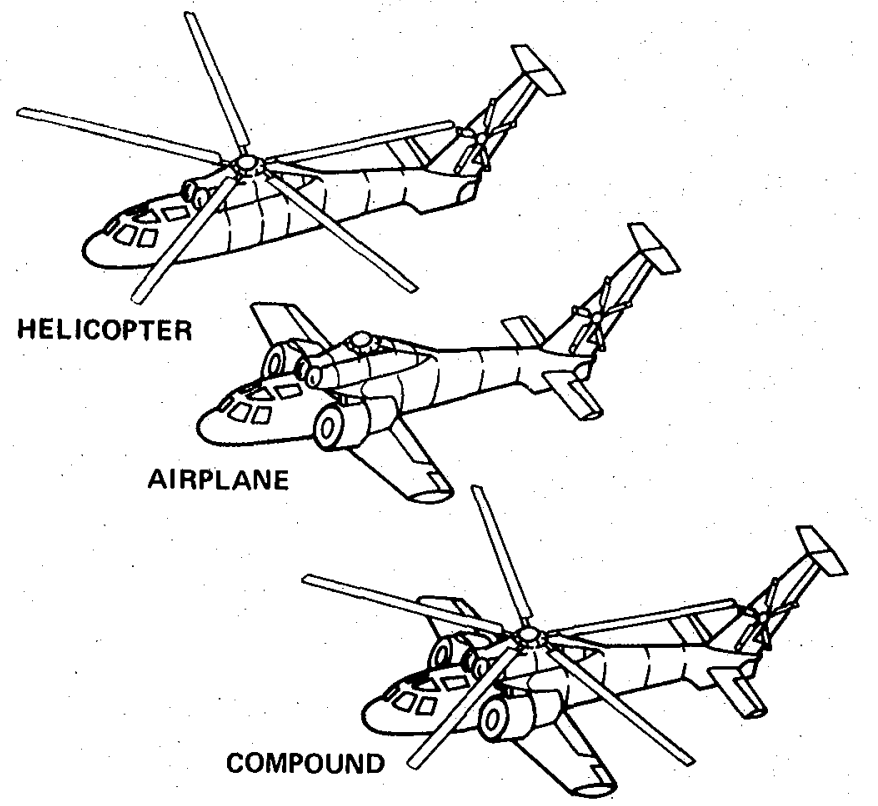

Fig. 1 RSRA flight configurations.

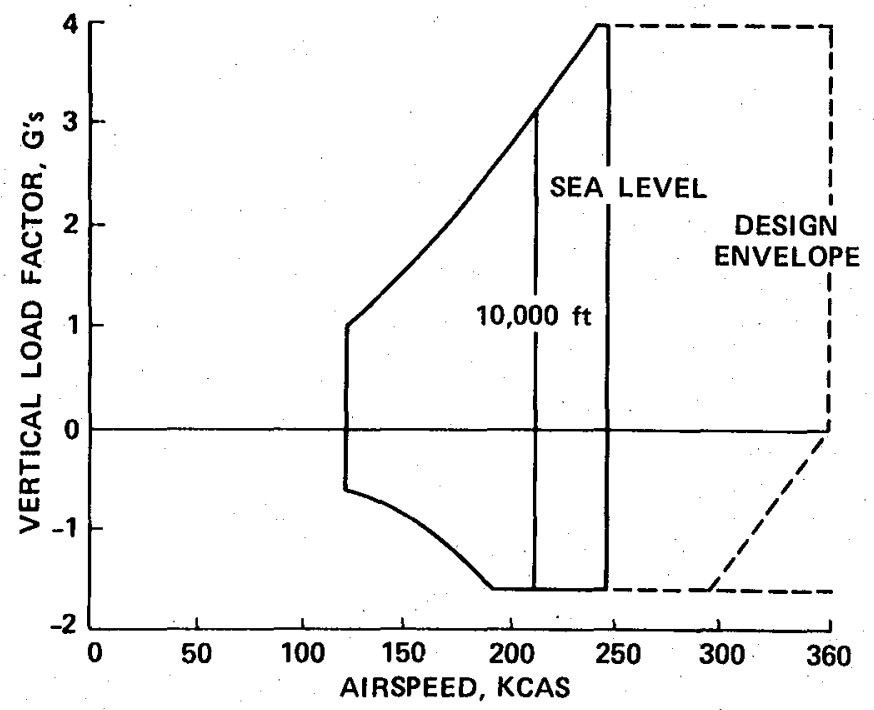

Fig. 2 RSRA planned fixed wing envelope development.

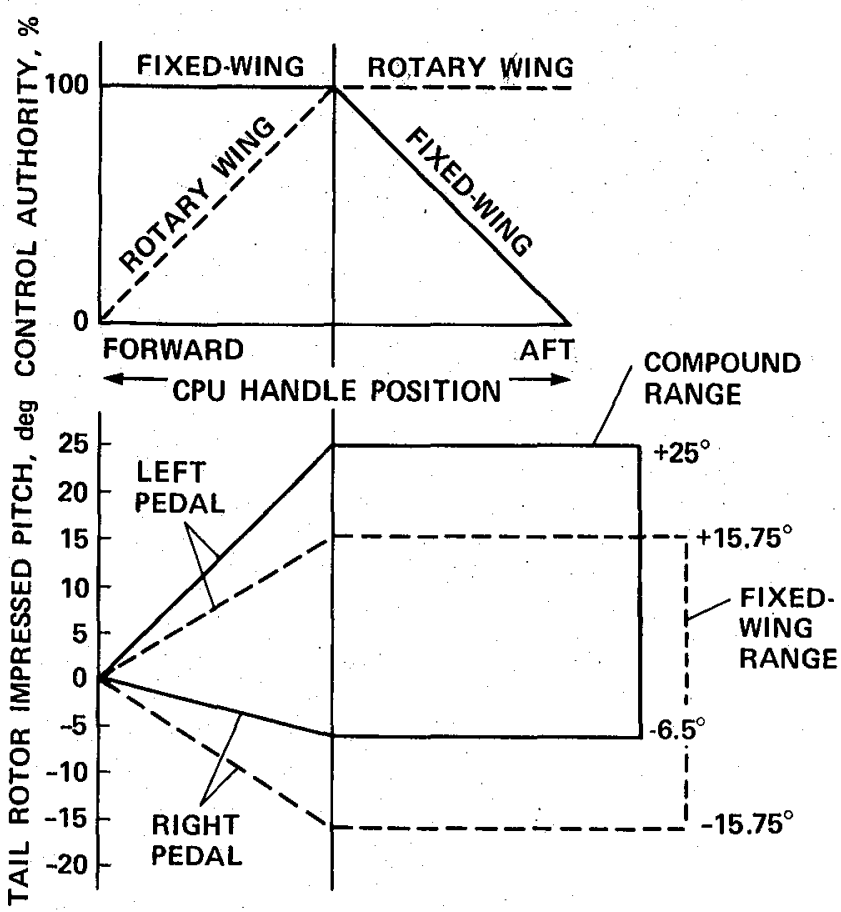

Fig. 3 Tail rotor control phasing unit.

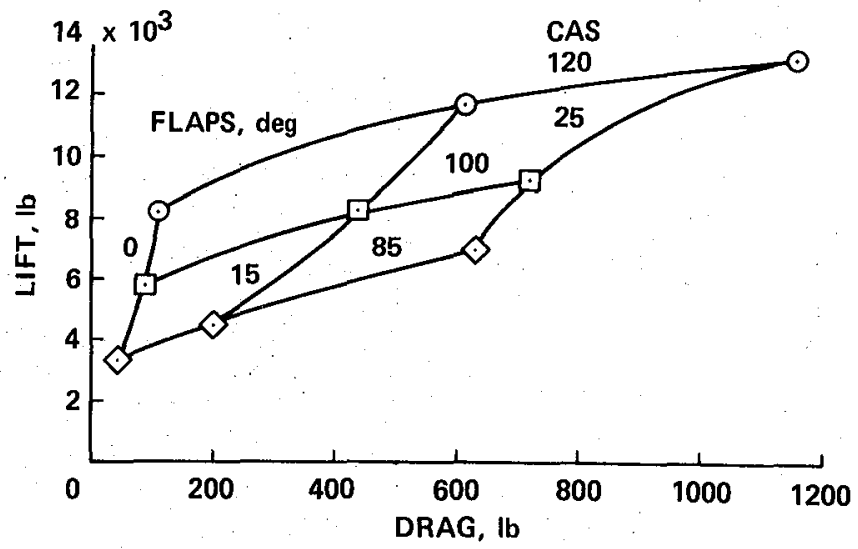

Fig. 4 wing lift vs. wing drag: $10^{\circ}$ wing incidence, $40 \%$ collective pitch. 


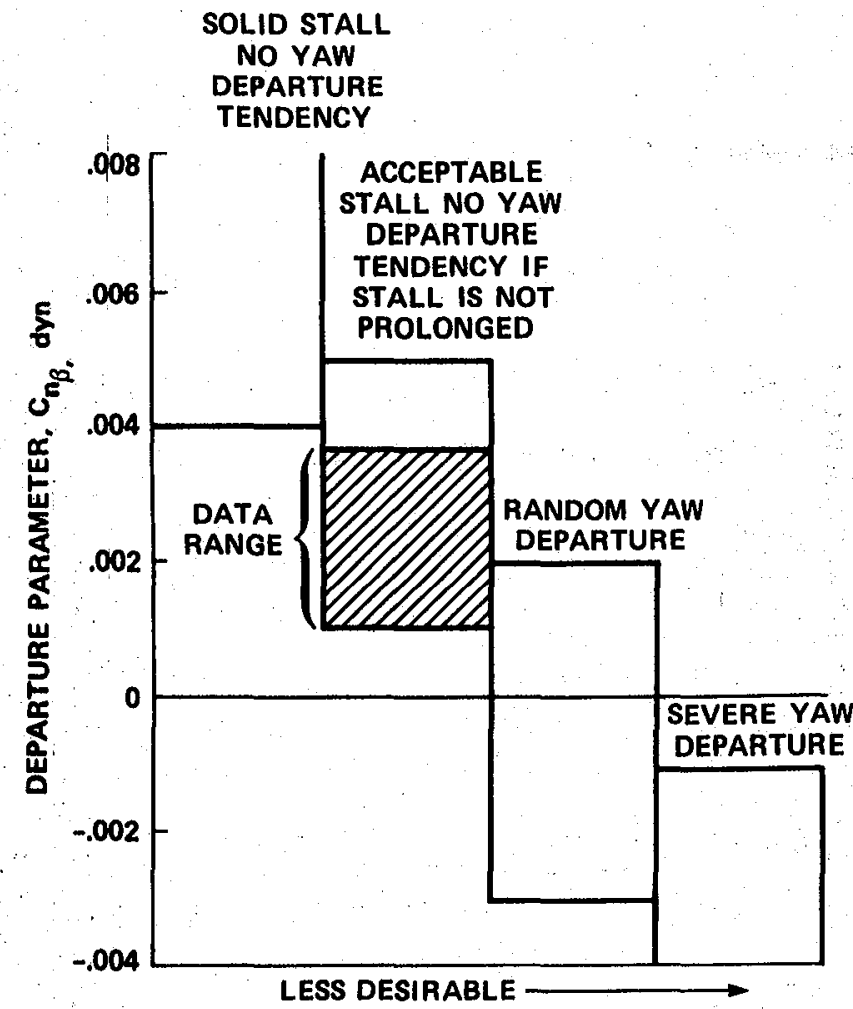

Fig. 5 Expected stall behavior as a function of $c_{n_{\beta}}, d y n$.

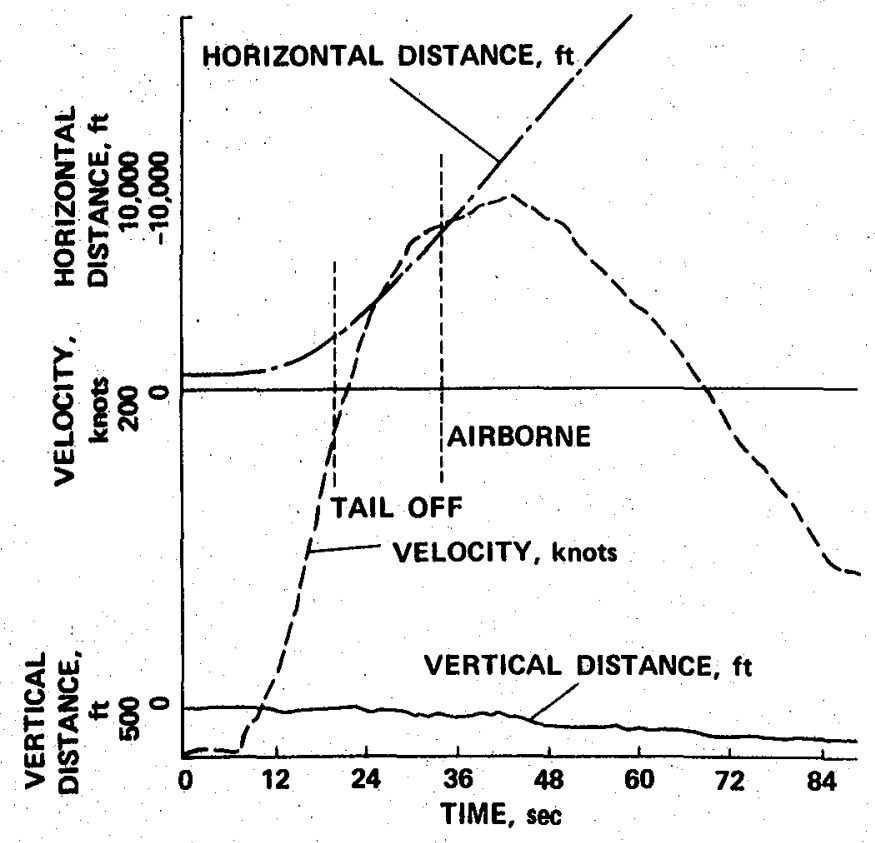

Fig: 6 RSRA fixed wing taxi-radar data, flight 5, run 24 .

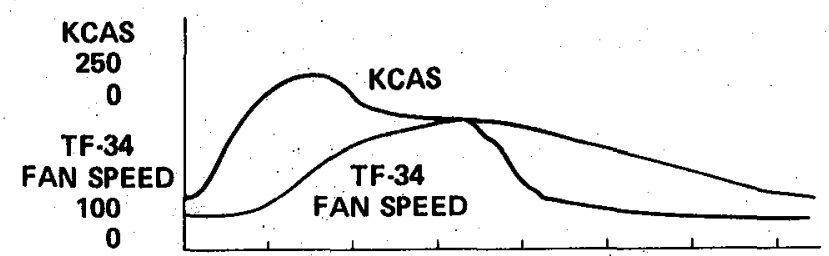

PEDAL POSITION, \%

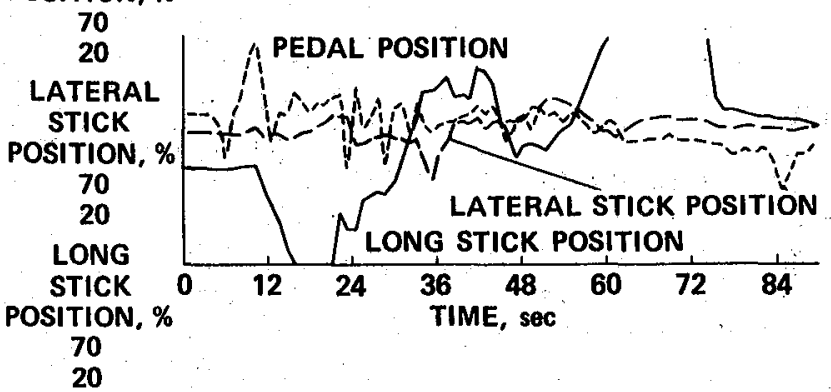

Fig. 7 RSRA fixed wing taxi.

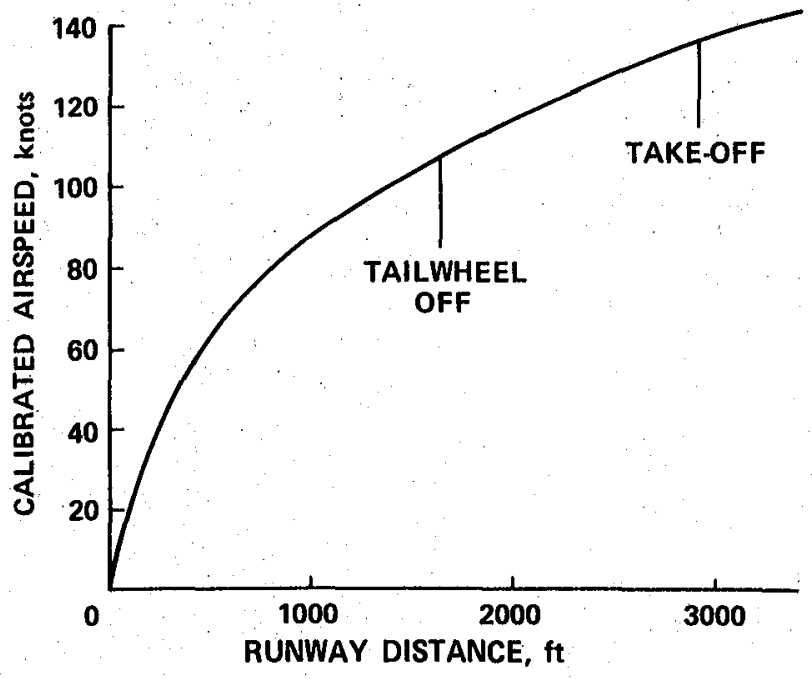

Fig. 8 RSRA fixed wing take-off, calibrated airspeed vs runway distance, radar, flight 6 . 


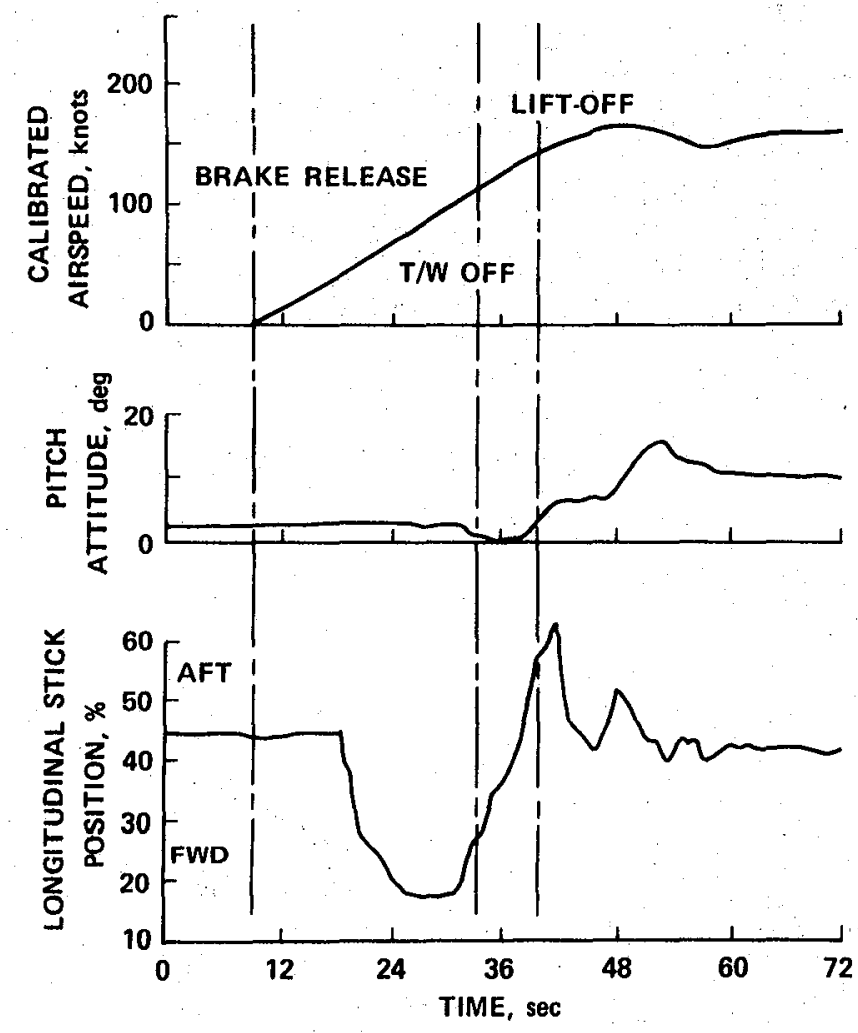

Fig. 9 RSRA fixed wing take-off, flight 6.
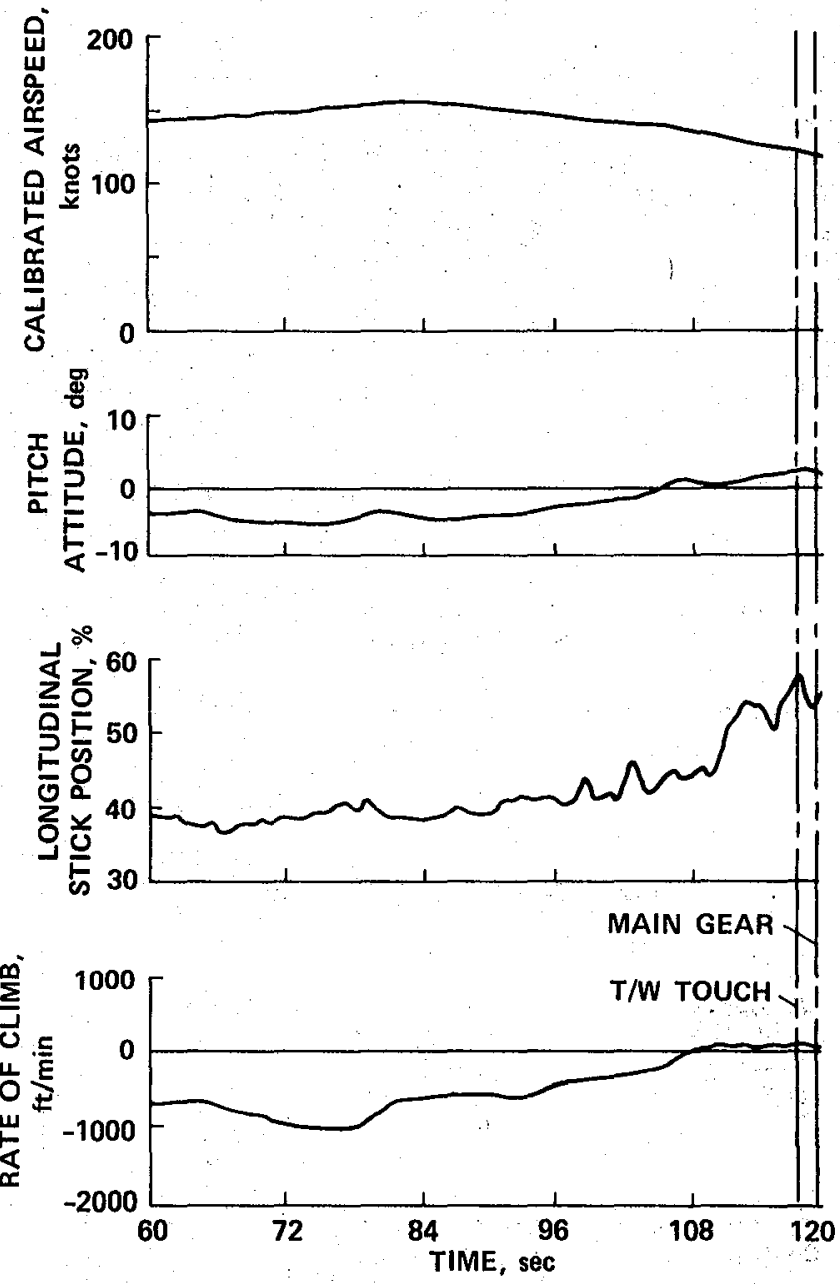

Fig. 10 RSRA fixed wing final approach and touchdown, flight 6 . 

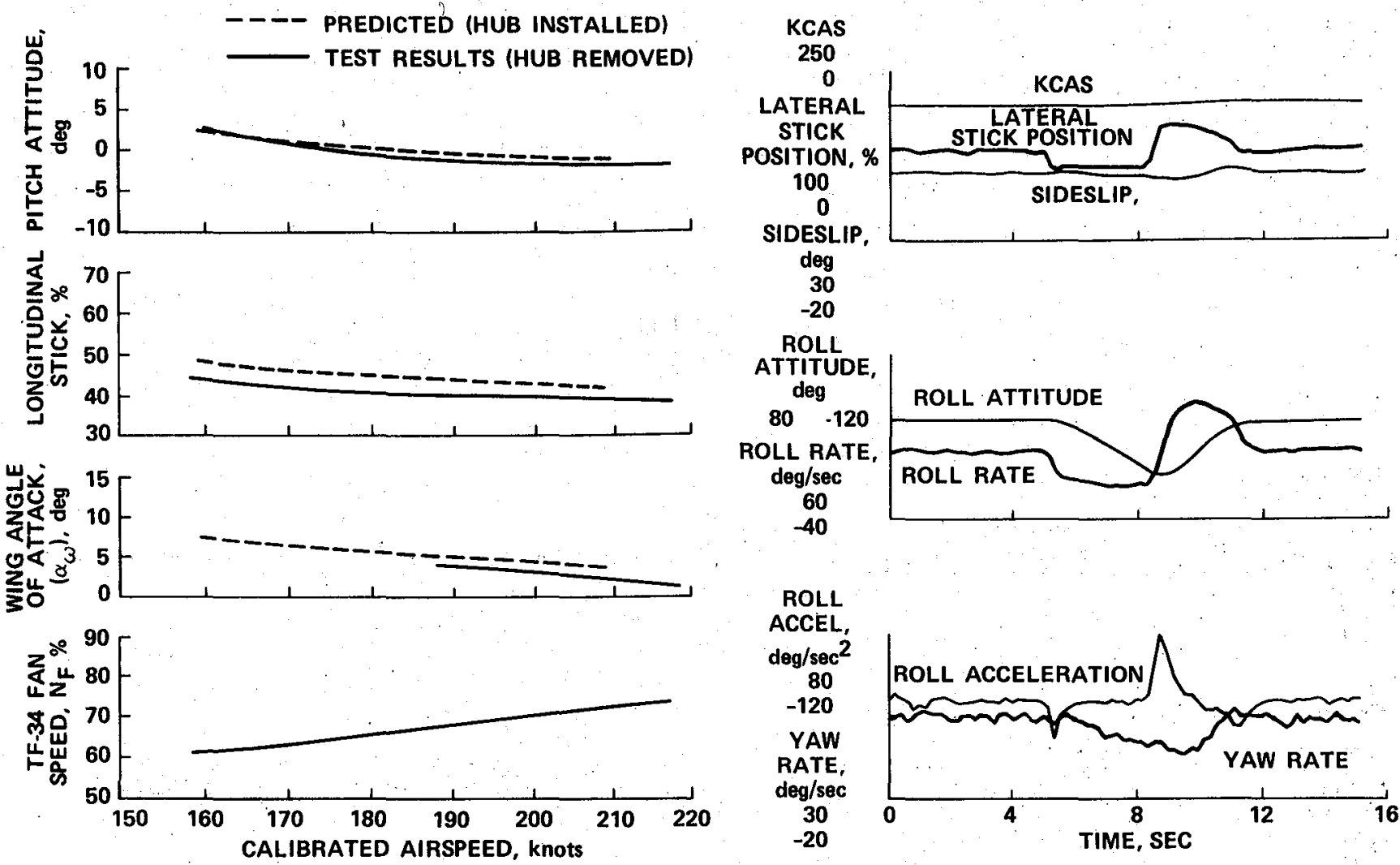

Fig. 11 RSRA fixed wing longitudinal trim: $I_{w}=5^{\circ}, \delta_{\text {FLAP }}=5^{\circ}, H_{d}=10,000 \mathrm{ft}$.

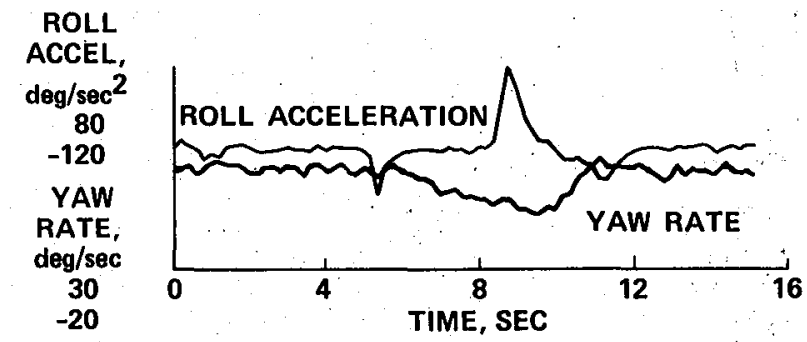

Fig. 13 RSRA fixed wing lateral step, 200 KCAS.
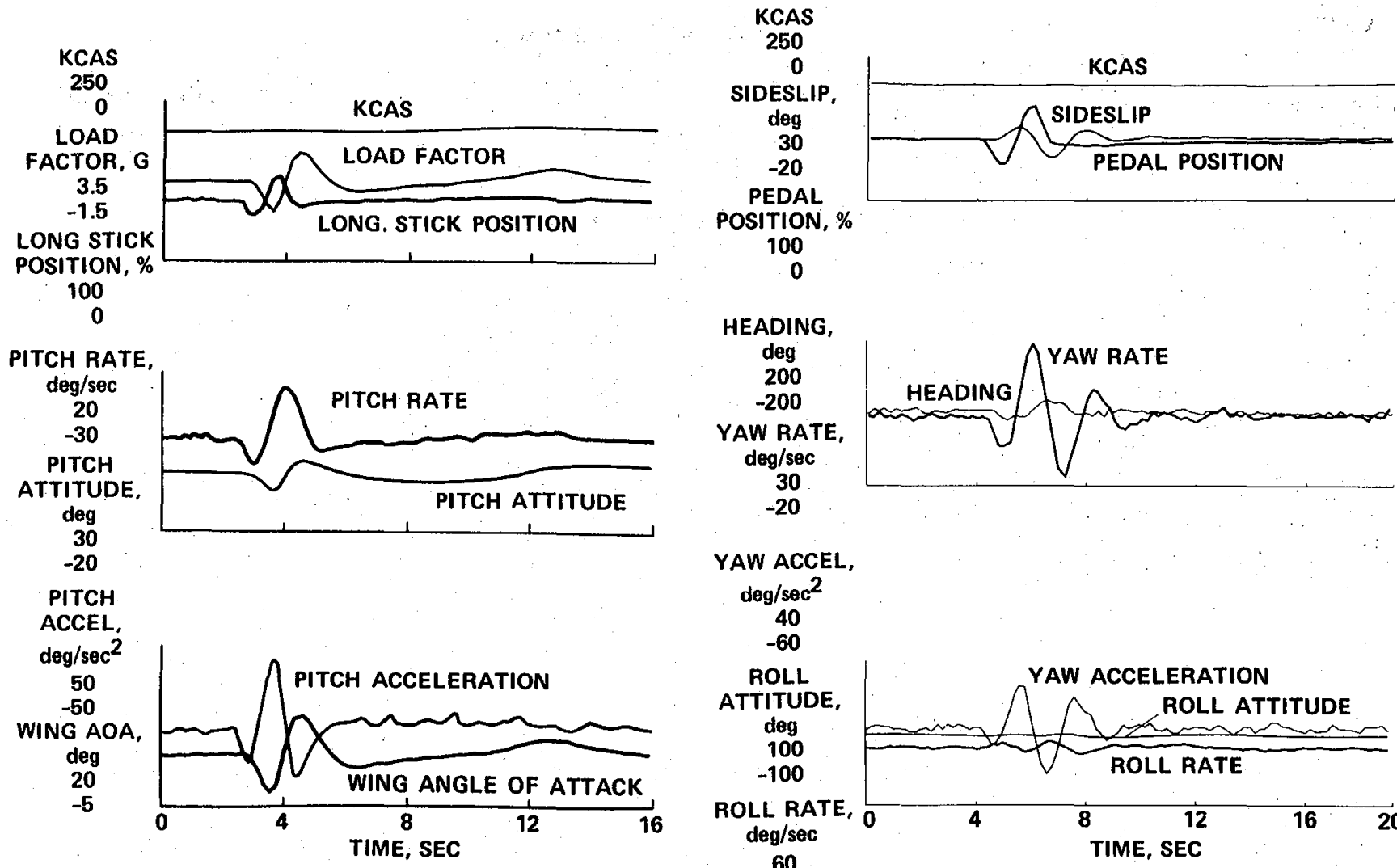

Fig. 12 RSRA fixed wing longitudinal doublet, 200 KCAS.
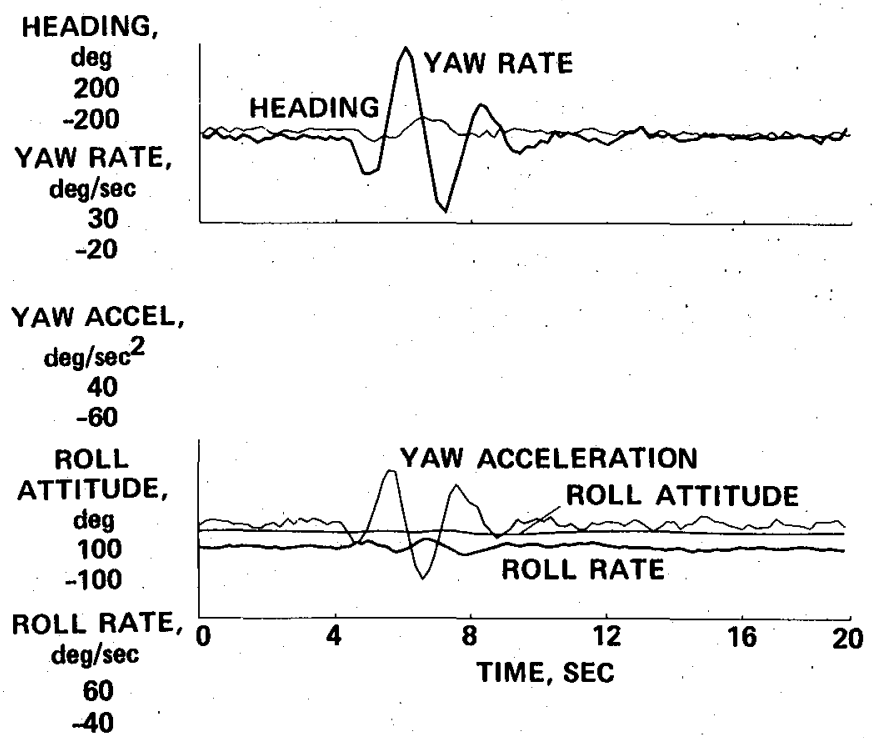

Fig. 14 RSRA fixed wing yaw doublet, 200 KCAS. 


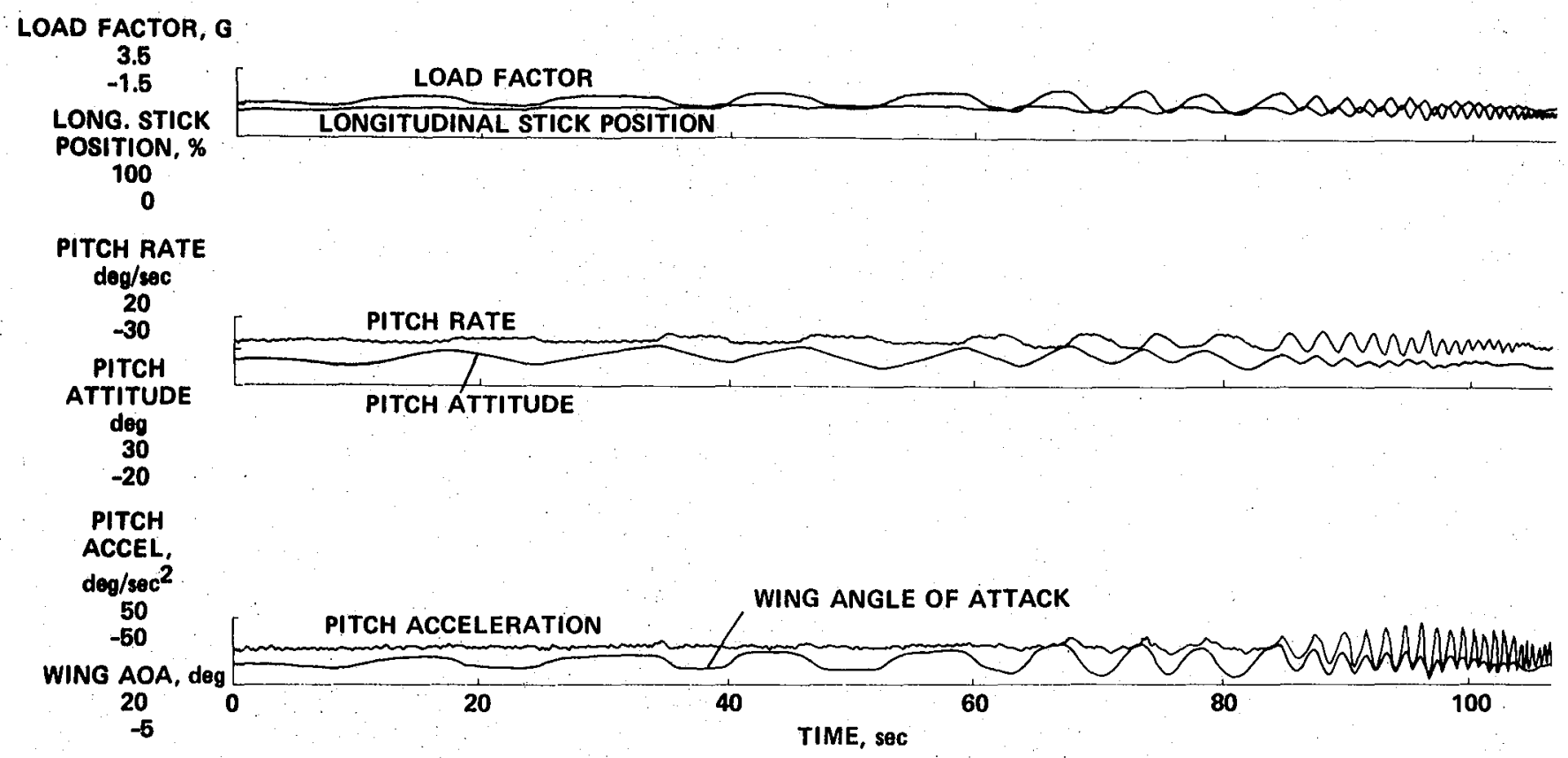

Fig. 15 RSRA fixed wing pitch sine input, 200 KCAS. 


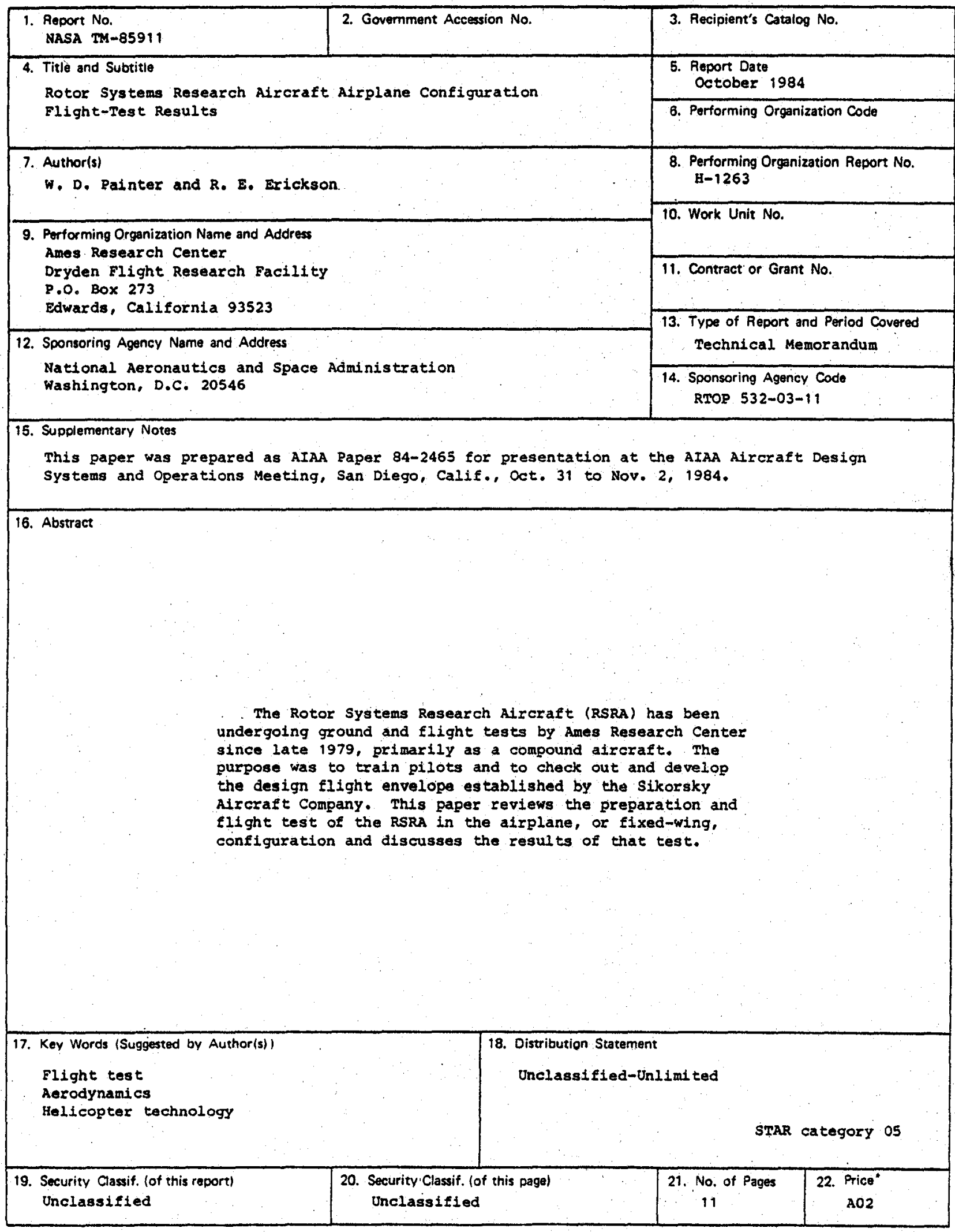

*For sale by the National Technical Information Service, Springfield, Virginia 22161. 
1

$\gamma$ 1 